\title{
روية لتطوير الإدارة العامه للشباب بمديرية الشباب والرياضة باسوان في ضوء إدارة التميز
}

الباحث/ زياد احمد يس حامد

الماخص

لا يخفى على أحد أهمية الدور الذي تلعبه المؤسسات الثبابية والرياضية في

خدمة المجتمع المصري ، ونتيجة للصعوبات والتحديات التي تواجه هذه المؤسسات كان لا بد من ووضع رؤية واقعية ، وبناء نظم إدارية وفنية معينة تعمل على تحقيق خدمات ذات جودة عالية ومتميزة تساعد على استمرار هذه المؤسسات في ظل التغيرات المتسارعة على المستوى العلمي والتكنولوجي الذي لم يدع هناك مكاناً للمؤسسات الضعيفة ، حيث تؤكد المؤشرات أن المستقبل سيفرز فقط المؤسسات المتميزة . فالتميز الإداري هو محصلة لنطبيق مجموعة من المعايير التي تمكن المنظمة من التوصل إلى نتائج تتافسية غير مسبوقة تزيد من الحصة السوقية وتساهم في زيادة

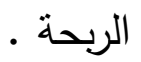

تهدف الدراسة إلى وضع روية لتطوير أسلوب العمل بالإدارة العامة للشباب بمديرية الثباب والرياضة بأسوان في ضوء إدارة التميز ، حيث تتمحور مشكلة الدراسة حول احتياج الإدارة العامة للشباب بمديرية الثباب والرياضة بأسوان إلى تطوير مستوى 
الأداء الإداري من واقع تطبيق إدارة التميز ، لمواكبة التطور العلمي والتكنولوجي والأساليب الإدارية الحديثة .

وقد أوصت الدراسة بضرورة العمل بأسلوب إدارة التميز ونشر ثقافة إدارة التميز للعاملين بالإدارة العامة للشباب بمديرية الثباب والرياضة بأسوان من خلال إعداد ورش عمل ومؤتمرات ودورات تدريبية ووضع معايير محددة لتقييم أداء العاملين بالإدارة العامة للشباب ، وكذلك ضرورة توفير كافة الإمكانات المادية اللازمة لتحقيق أهداف العمل بالإدارة العامة للشباب والعمل على توضيح وتوصيل أهداف ورسالة ورؤية الإدارة العامة للشباب للمستفيدين من أنشطتها بأسوان وتشكيل فريق عمل متميز داخل الإدارة العامة للشباب قادر على تحقيق رغبات واحتياجات المستقيدين وتجاوز توقعاتهم على قدر المستطاع ومنح جوائز للعاملين المتميزين بالإدارة العامة للثباب ، والحرص على تطوير السياسات والاستراتيجيات الداعمة لإدارة التميز .

\section{مقدمة ومشكثة البحث :-}

إن البحث عن أسـاليب حديثة في الإدارة كان مطلباً حثيثاً محاولـة للتأقلم مـع المتغيرات العالميـة التي زادت من حدة التتافسية وغيرت مـن طبيعـة إنجاز الأعمال كنتيجة للنطور الهائل في عالم التكنولوجيا والاتصالات وسطوة العقل البشري ، حيث شكل مدخل إدارة التميز نموذجاً مهماً للإِدارات بإدارتها الحاليـة وعاملاً مسـاعداً لها لبقاءها واستمرارية نجاحه تطويرها المستقبلي. ( T I ) ) وقد ظهر مفهوم إدارة التميز للتعبيرعن الحاجة لمدخل شامل يجمع عناصر ومقومـات بنـاء المنظمـات على أسس متفوقـة تحقف لهـا قدرات مثاليـة في مواجهـة 
المتغيرات والأوضاع الخارجية المحيطة بها ، كما تكفل تحقيق الترابط والتتاسق الكامل بين عناصرها ومكوناتها الذاتية واستثمار قدراتها المحورية والتفوق ، ومن ثم فإن إدارة التميز هي القدرة على توفيق وتتسيق عناصـر المنظمة وتتكبلها في تكامل وترابط لتحقيـق أعلى معدلات الفاعليـة والوصـول بـذلك إلى مستوى المخرجـات الذي يحقق رغبات ومنافع وتوقعات أصحاب المصلحة المرتبطة بالمنظمة .( rا : (Y، • ) ) حيث تعد إدارة التميز أحد الدفاهيم الإدارية الحديثة التي تسعى إلى تطوبر نظـم وأسـاليب العمل والارتقـاء بـه مـن خـله تفعيـل كافـة عناصـر العمليـة الاداريـة وتتغيلها في تكامل والتتسيق بينهـا بما يضمن الوصـول إلى أفضل معدلات الأداء بحيث تكون المخرجات العلميـة الإداريـة متوافقة مـع رغبات المستقيدين من المنظمـة) $(r \cdot:) r$ مفهوم التميز أو ما يسمى بـ ( Excellence ) في اللغة الإنجليزية ليس حديث الاكتشاف حيث تشير الدراسات إلى أن المفهوم كان يستخدمه الإغريق بمفهوم ) والذي تعني نرجمته إلى الإنجليزية (Best braver mightter) أي أفضل الأحوال شجاعة وأكثر هولا ، أما عند الإغريق فقد كان أصل الكلمة يتكون من مقطعين الأول ( AR ) ويعني تدفق الضوء أو الخير والثاني (ISTON) والتي تعني $(r \cdot 9: 19)$ الاستقرار والتوافق ويمكن تعريف إدارة التميز : تلك الجهود التنظيميـة المخططـة التي تهـدف إلى تحقيـق الميزات التتافسية الدائهـة ل المنظمة . ( ) ( ) (1) 
كما عرفه النموذج الأوروبي لعام (r +. rم )بانها " ثلك الممارسـ المتأصله فى ادارة المنظمه وتحقيق النتائج، التى ترتكز على مجموعه من المعايير الجوهريه ". ( r:^ ) تقوم ادارة التميز على مبدا تفويض السلطة للعاملين بكافة المستويات الداريـة داخل المنظمـة وفيها يتم العمل لتحقيق الجودة من خـلال قيـادة رشيدة تعمل على تشـيع

$$
\text { وتوجية الأفراد. ( ) ( }
$$

ويرجع "جريج رود" Gerardo" "ان المنهج الإداري الذى تسنطيع المنظمة من خلاله التميز، يجب ان يدعم السلوكيات الإدارية التي من شانها الإرتقاء بمستوى الأداء من

$$
\text { اجل تحقيق اهداف المنظمة .) ( I (OV: }
$$

وتعرف " راويـة محمد حسن " العمل الإداري انه يشير إلى درجة تحقيق إتمام المهام المكونـة لوظيفة الفرد ، وهو يعكس الكيفيـة التي يحقق أو يثبع بها الفرد متطلبات الوظيفة ـ وغالباً ما يحدث لبس وتداخل بين الأداء والجهد ، فالجهد يثير إلى الطاقة المبذولة ، أما الأداء فيقاس على أساس النتائج التي حققها الفرد (T: 7 (Y) كما يعرفه " أحمد صقر عاشـور "على أنه قيام الفرد بالأنشطة والمهام المختلفة التي

$$
\text { يتكون منها عمله (1: ب (Y) }
$$

وظهرت في الأونة الأخيرة زيادة اهتمام المنظمات بما يعرف بإدارة التميز سعياً للتكيف مـع بيئة الأعمـال الجديدة وإفرازات العولمـة وحدة التتافسية وقد بـات لزامـاً على كل 
منظمـة تسعى إلى البقاء والاستمرار امتلاكها نظام إداري قوي وفعال لمواكبة النجاح

$$
\text { والتقدم • ( IV) ( ) }
$$

ومن خلال عملي بالإدارة العامة للثباب بمديرية الثباب والرياضة بأسوان كأخصائي مسئول عن مكتب ذوي القدرات والهمح فقد لاحظت أن اسلوب العمل الإداري بالإدارة العامة للشباب لا يتماشى مع المتغيرات الحديثة في الأساليب الإدارية ، مما يقف عائقاً أمام تقدمها وتطويرها ، ووجود صعوبة في التواصل بين الإدارة العامـة للثباب والإدارات الثبابية ومراكز الثباب والهيئات الثبابية التابعة لها ، ونظراً للتطورات الهائلة التي تشهـها الساحة العالمية في شتى المجالات وخاصـة مجال الإدارة الرياضية ، ذلك الأمر الذي دعا إلى ضرورة الاتجاه إلى مواكبة تلك التطورات وذلك عن طريق استخدام الأسـاليب الحديثة في إدارة تلك الهيئات والمؤسسـات وذلك في سبيل تحقيق الارتقاء والتقدم والنهوض بهذه الهيئات والمؤسسات الثبابية ، مما استدعى الباحث إلى هذه الدراسة للتعرف على الواقع الفعلى للعمل الإداري للإدارة العامـة للشباب ووجود إدارة حديثة تعدل على الارتقاء بمستوى العمل الإداري في الإدارة العامة وفروعها من خلال اتجاه إداري حديث ( إدارة التميز). ومـن خـلال العرض السـابق وفي حدود علم الباحثث ومـا اطلـع عليـه مـن الأبحـاث والدراسات السابقة التي تتطرق إلى هذا المجال البحثي ، لم يجد من الأبحاث والدراسات 
العلمية المرجعية التي تتـاول دور إدارة التميز في تطوير العمل الإداري داخل الإدارة العامة للشباب بمديرية الثباب والرياضة ، وكان في حد ذاته من أحد الدوافع الحقيقية لإجراء هذا البحث .

وكذلك من خلال طبيعة عمل الباحث كأخصائي رياضي بالإدارة العامة للشباب

بمديرية الثباب والرياضة بأسوان لاحظ أن الإدارة بحاجة إلى تطبيق إدارة التميز لرفع مستوى الأداء وتحديث أسلوب العمل بالثكل الذي يتتاسب مع متطلبات التطور العلمي والتكنولوجي وأساليب الإدارة الحديثة والمنطورة .

\section{أهمية البحث:}

يتضح أهمية هذا البحث في كونه يطبق على المجتمع المصري حيث تتادي قطاعات الدولـة في تطويره وتتميته والرفع من مسـتواه الإداري ، وبمكن تحديد أهميـة البحث والحاجة إليه في النقاط التالية:ا . قد يساهم في تطوير العمل الإداري داخل الإدارة العامة للشباب بمديرية الثباب

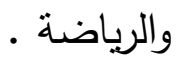
r قد يساعد هذا البحث على وضـع قواعد للعمل داخل الإدارة العامـة للشباب من خلال اتباع اتجاه إداري حديث ( إدارة التميز) 


\section{أهدف البحث: : n}

التعـرف على دور إدارة التميـز في تطـوير العهـل داخـل الإدارة العامـة للثـباب

$$
\text { بمديرية الثباب والرياضة بأسوان من خلال التعرف على : }
$$

ا الواقع الحسالي للعمل الإداري بـالإدارة العامـة للثـباب بمديربـة الثـباب والرياضــة

$$
\text { بأسوان. }
$$

r ـ متطلبات تطبيق إدارة التميز لتطوير العمل الإداري بالإارة العامة للشباب .

$$
\text { : تساؤلات البحث: }
$$

ا ـ ما الواقع الحالي للعمل الإداري بالإدارة العامة للثباب بمديرية الثباب والرياضـة

$$
\text { • بأسوان }
$$

r ـ ما متطلبات تطبيق إدارة التميز لتطوير العمل الإداري بالإدارة العامة للشباب .

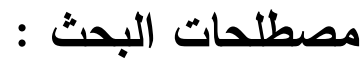

\section{1- إدارة التميز ( Excellence)}

تلك الجهود التتظيميـة المخططـة التي تهـدف إلى تحقيـق الميززات التتافسية الدائمـة

$$
\begin{aligned}
& \text { للمنظمة . (0 : } 7 \text { ) } \\
& \text { العمل الإداري : }
\end{aligned}
$$


ويعرفه آخرون على أنه قدرة الإدارة على تحويل المدخلات الخاصـة بالتنظيم إلى عدد

$$
\text { من المخرجات بمواصفات محددة وبأقل تكلفة ممكنة . ( ع ا : (0) ) }
$$$$
\text { r- الإدارة العامة للشباب بمديرية الثباب والرياضة بأسوان : }
$$

وهي إحدي أهم الوحدات الإدارية المركزيـة المكونـة للهيكل التتظيمي لمديريـة

الثباب والرياضـة بأسوان ، وهي تقوم على تتفيذ أنشطة مختلفة منها ( الرياضية والفنية ، والثقافية ، والكثفية ، والعلمية ، والتطوعية ، والاجتماعية ) من شأنها خدمة المجتمع الأسواني في العموم والثباب من سن ^1 إلى سن هب سنة على وجهـ الخصوص بحيث تقدم هذه الخدمات وتتفذ هذه الأنشطة بشكل مباشـر أومن خـلال مراكز الثباب والهيئات الثبابية وذلك بحسب التوصيف الإداري للجهاز المركزي للتنظيم والإدارة

\section{دراسات سابقة :}

ا ـ ـ دراسـة " تغريد عيد الجابري " ( 9 . . rم) (0 ) بعنوان دور إدارة التميز في تطوير أداء مؤسسات التعليم العالي في الضفة الغربية ، واستهدفت الدراسة التعرف على مدى فاعلية إدارة التميز ومسـاهماتها في إحداث تطوير لأداء مؤسسات التعليم العـالي في الضفة الغربيـة ، واستخدمت الباحثة المنهج الوصفي ، وتم اختيار عينـة الدراسة من أفراد مجتمع الدراسة المتمنل في الإدارة العليا ورؤساء 
ونـواب وحدات الجودة في مؤسسـات التعليم العـالي في الضـفة الغربيـة واستخدمت الاستبيان كأداة لجمع البيانـات كما بينت النتائج أن مستوى الأداء لمؤسسـات التعليم العالي متوسط ويوجد تفاوت بين تلك المؤسسات فيما بتعلق بمدى امتلاكها وممارستها

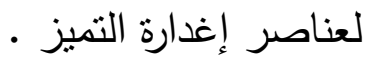

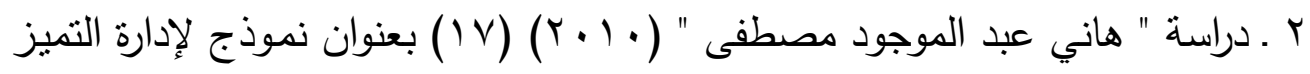
لتطـوير الأداء الإداري بالاتحـادات الرياضـية والأوليمبيـة بجمهوريـة مصـر العربيـة " واسـتهدفت الدراسـة وضــع نــوذج لإدارة التميـز لتطــوير الأداء الإداري بالاتحـادات الراياضـية والأوليمبيـة بجمهوريـة مصـر العربيـة ،واسـتخدم الباحث المـنهج الوصـي ، وكانت العينـة ( ؛ (1 ) فرد كعينة أساسية و ( • ) أفراد كعينـة استطلاعية ، واستخدم الباحث استمارة استبيان كأداة لجمع البيانات وكانت أهم النتائج التوصل إلى نموذج لإدارة التميز لتطوير الأداء الإداري بالاتحادات الراياضية والأوليمبية بجمهورية مصر

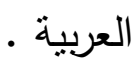

rilson Robrto Theobald Brto ب ـ دراسة كلاً من روبرتو ثيوبلاد وجيلسون بريت بعنوان إدارة التميز كمنهج لإدارة العمل البشري ، واستهدفت الدراسـة (Y . . V) التعرف على امكانية استثمار العوامل البشرية كعنصر أساسي في العملية الإدارية نحو تحقيق النطوير الإداري ، واستخدم الباحثان النهج الوصفي ، وكانت أهم النتائج اقتراح 
" هيكل مفاهيمي " لدمج العامل البشري سواء العاملين أو أصحاب المصلحة المنتقعين في المنظمة في فاعليات العمليات الإدارية لتحقيق التميز الإداري

Pui -mun I and Hesan A. Quaz دراسة ط بيومان وهيسن كوزي . .

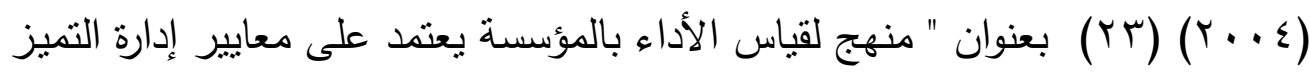
" واسـتهدف تصــيم أداة لقيـاس الأداء بالمؤسسـة يعتمــ على معـايير إدارة التميـز ، واستخدم الباحثان المنهج المسحي ، وكانت أهم النتائج أن استخدام نماذج الجودة في Self- assessment تصميم وسيلة أو أداة القياس الذاتي للتحقق من مدى تطبيق إدارة الجودة الثـاملة وفق العناصر المحددة بجوائز الجودة • بحقق التتمية الإدارية بشكل كبير

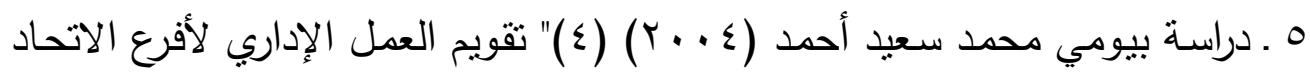
المصـري لكرة اليــ بمحافظـات صـعيد مصـر" واستهدفت ثقيم العمل الإداري لأفرع الاتحاد المصري لكرة اليد بمحافظات جنوب صعيد مصر ، واستخدم الباحث المنهج الوصفي ، وكانت عينـة البحث متمنلـة في أعضـاء مجالس الإدارات لأفرع الاتحـاد المصري لكرة اليد بمحافظات جنوب الصعيد ، وكانت أهم النتائج هي ضعف عناصر العملية الإدارية ( التخطيط ـ التوجيه ـ الرقابة ـ قياس الأداء ) بأفرع الاتحاد المصري لكرة اليد بمحافظات جنوب الصعيد. 


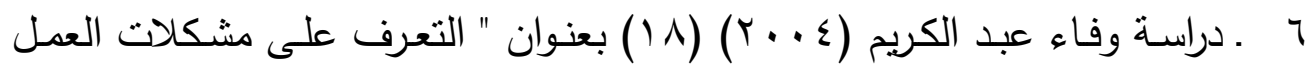
الإداري بمراكز الثـباب" ، واسـتهدفت الدراسـة التعـرف على مشكلات العمل الإداري بمراكز الثباب ، والتي تختص بالتخطبط والتنظيم والرقابة ، واستخدمت الباحثة المنهج الوصفي ، وكانت عينة البحث متمنلة في عينتان الأولى تشمل مديري مراكز شباب المدن وقوامها (YrV) والعينـة الثانيـة مـن القيـادات الإداريـة بـوزارة الثـباب والرياضــة ومديري مديريات الثباب والرياضة متمنلة في († Y) محافظة ، وكانت أهم النتائج هي وجود عدة مشكلات للعمل الإداري بمراكز الثباب وهي مشكلات تختص بـ ( التخطيط • والتظيم ـ التوجيه ـ والرقابة ) . خطة وإجراعات البحث : منهج البحث : اسـتخدم الباحـث المـنهج الوصـفي وذلــك لملاعمتـه لطبيعـة البحـث حيـث يسـهم فـي تحقــق طبيعـة البحـث المرجـوة مـن خـلال التعـرف علـى الطبيعـة الحقيقيـة للمجتمع الأصلي " قيد البحث ".

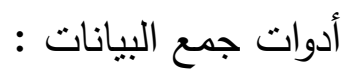
الملاحظة • المقابلة

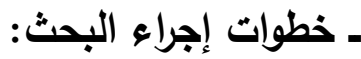


ب ـ التحليل المرجعي للاراسات السابقة .

ومـن خـلال التحليـل اللحظـي للعـاملين في الإدارة العامـة للثـباب بمديريـة الثـباب

$$
\text { والرياضة بأسوان رأى الباحث الأتي :- }
$$

1 - وجود بعض الأقسام داخل الإدارة لا تعمل بأسلوب إدارة التميز مما يجعلها في

التقييم أقل من غيرها في مستوى الأداء من الأقسام الأخرى .

r - احتياج بعض العاملين بالإدارة العامة للثباب للتعرف على ثقافة التميز الإداري

لقلة حضورهم لورش العمل والدورات التدريبية أو المؤتمرات التي من شأنها زيادة الوعي بأهمية تميز الأداء . - مئ.

r ـ العجز في بعض الإمكانيات المادية في الإدارة يحول دون الوصول الي الهدف الرجو الا وهـو اسـتخدام أسـلوب إدارة التميز في تقيم مسـتوي الأداء بـالإدارة العامـهـ

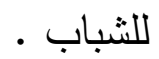
ع ـانعدام الرؤيـة لدي المستقفيدين مـن أنتطة الإدارة العامـه للشباب قد يؤدي الي عزوف بعضهم عن المشاركة في هذه الالنشطة والاستفاده منها بشكل فعال. ه . عدم التتاغم بين فريق بين فريق العمل بالإدارة العامه للشباب يؤثر في انخفاض مستوي الأداء بما لا برقي الي الوصول بالعمل بأسلوب إدارة التميز • 
1 ـ ضـرورة العمل بأسلوب إدارة التميز داخل الإدارة العامـة للشباب بمديريـة الثـباب • والرياضة بأسوان r نشر ثقافة إدارة التميز للعاملين بالإدارة العامة للشباب بمديرية الثباب والرياضـة بأسـوان مـن خـلال إعداد ورش عمل ومـؤتمرات ودورات تدريبيـة متخصصـة في هذا • الثأن r ـ وضع معايير محددة لتقييم أداء العاملين بالإدارة العامة للشباب ، وكذلك ضرورة توفير كافة الإمكانات المادية اللازمة لتحقيق أهداف العمل بالإدارة العامة للشباب .

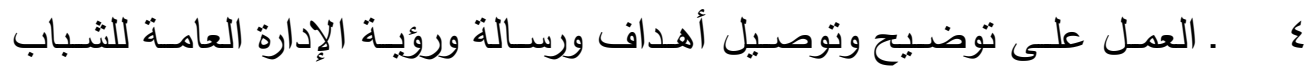
للمستفيدين من أنشطتها بأسوان. ه تشكيل فريق عمل متميز داخل الإدارة العامـة للشباب قادر على تحقيق رغبات واحتياجات المستقيدين وتجاوز توقعاتهم على قدر المسنطاع • 7 ـ ـنح جوائز للعاملين بالإدارة العامة للشباب تحفيزاً لهم على إنجازاتهم . V . الحرص على تطوير السياسات والاستراتيجيات الداعمة لإدارة التميز . 


\section{المراجع}

$$
\text { أولاً : المراجع العربية : }
$$

ا ـ أحمد صقر :السلوك الإنساني في المنظمات ، دار المعرفة الجامعية ،

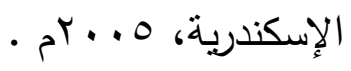

r ـ أحمد محمد أحمد :القيادة الإبداعية وإدارة التغيير والتطوير ، الإدارة

الاستراتيجية والتميزالإداري ، المؤتمر العربي السنوي الخامس في الإدارة

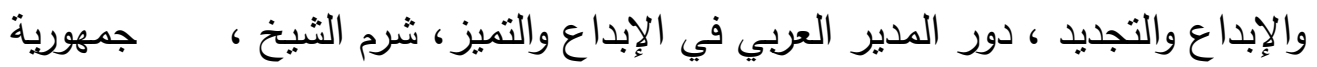

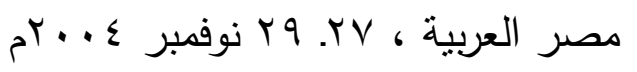

r ـ أسعد محمد أحمد :" أثز الثقافة التتظيمية على مستوى الأداء الوظيفي ، رسالة ماجيستير غير منشورة كلية التجارة ، الجامعة الإسلامية بغزة ، 1 .. بم. ـ ـ بيومي محمد سعيد: تقويم العمل الإداري لأفرع الإتحاد المصري لكرة اليد بمحافظات جنوب الصعيد بمصر ، رسالة ماجستير ، كلية التربية الرياضية جامعة

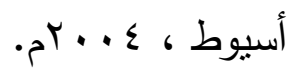

ه ـ تغريد عيد الجعبري :" دور إدارة التميز في تطوير أداء مؤسسات التعليم العالي في الضفة الغربية "رسالة ماجستير غير منشورة كلية الدراسات العليا والبحث العلمي ،

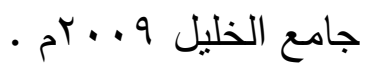

7 ـ راوية محمد حسن :إدارة الموارد البشرية المكتب الجامعي الحديث ، الاسكندرية

V . شامي صليحة : المناخ التظيمي وأثزه على الأداء الوظيفي للعاملين ، كلية العلوم الاقتصادية والتجارية وعلوم التيسير ، جامعة بومرداس • ( • بم • 
^ ـ شلبي السوبطي : واقع إدارة الجودة الثاملة في جامعة القدس المفتوحة ، كتاب بحوث المؤتمر الثالث لاتحاد نقابات أساتذة وموظفي الجامعات الفلسطينية ، الجودة والتميز والاعتماد في مؤسسات التعليم العالي جامعة القدس ، V. . ب م. 9 ـ صالح بن سليمان :نحو بناء إطاراً منهجياً للإببداع وتميز الأعمال في المنظمات العربية ، المؤتمر العربي السنوي الخامس في الإدارة والإبداع والتجديد ، دور المدير العربي في الإبداع والتميز شرم الثيخ ، جمهورية مصر العربية ، 9 ج. VY نوفمبر $\cdot a^{r} \cdot \operatorname{s}$

• 1 ـ عبد اله الكندري : أثز العدالة التنظيمية على فاعلية الأداء الوظيفي ( بالتطبيق على أعضاء هيئة التدريس بجامعة الكويت ) رسالة ماجستير غير منشورة ، كلية التجارة ، جامعة عين شمس بـ +. r م. 11 ـ علي أحمد عبود : إدارة الجودة الثاملة مدخل منكامل لتطوير الأداء بالدوائر المحلية بحكومة دبي ، رسالة دكتوراة في الفلسفة في إدارة الأعمال ، كلية التجارة ، جامعة عين شمس ، مصر ، ب ... rم. r ـ ـ علي محد السلمي :" إدارة الموارد البشرية الاستراتيجية " مكتبة دار غريب ،

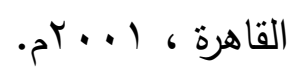

" ـ ـ علي محمد السلمي : " إدارة التميز نماذج وتقليات الإدارة في عصر المعرفة "

$$
\text { ، مكتبة دار غريب ، القاهرة ب. . ب م. }
$$

ع ا ـ محمد بن العزبز :علاقة الجودة الثاملة بالأداء الوظيفي في القطاع الصحي من وجهة نظر العاملين في مركز الأمير سلطان معالجة أمراض وجراحة القلب للقوات المسلحة بمدينة الرياض ، رسالة ماجستير في العلوم الإدارية ، كلية الدراسات العليا ، أكاديمية نايف العربية للعلوم الأمنية ، السعودية، ب . . بم • 
10 ـ محمد كمال أميري وعصام بدوي : " التطور العلمي لمفهوم الرياضة " ، مكتبة النهضة المصرية ، القاهرة ع99 امبه

17 ـ نانيس عبد الحافظ : علاقة ضغوط العمل بفاعلية الأداء الوظيفي للمرأة العاملة ، دراسة تطبيقية على الكليات جامعة القاهرة الكبرى ، رسالة ماجستير غير منشورة ، القاهرة ، جامعة حلوان ، كلية التربية الرياضية بنين بالهرم • ( • بم IV ـ هاني عبد الموجود مصطفى :" نموذج مقترح لإدارة التميز لتطوير الأداء الإداري بالاتحادات الرباضية والأوليمبية بجمهورية مصر العربية " رسالة ماجستير غير منشورة بالقاهرة ، جامعة حلوان كلية التربية الرياضية بنين بالهرم ، · 1 • آم . 1 ـ ـوفاء عبد الكريم : "دراسة تحليلية لمشكلات العمل الإداري بمراكز الثباب " رسالة ماجستير كلية التربية الرياضية للبنات ، القاهرة بجامعة حلوان ، ع . . بم.

$$
\text { ثانياً : المراجع الأجنبية :- }
$$

19 -Anninos, LoukasN:'The archetype of excellence in69 universities and

TQM " , Journal of management History vol.13 No.4,pp 3212007

20-. Badri, masood abdlua. selim. hassan, alshare, khaled grandon, Elizabeth e., younis hassan : the baldrige education criteria for proformance Excellenc eframe workempirical testand validation Journal of

21- Greigrod: managing for excellence 2009.

22-james c becer :the important of individual performance from

23-the perspecitive of gnome and ongoingtional performance effectiveness'small group research' vol 


\section{2- 2001.}

24-pui-mun lee and hesan a: Quazi:design methodology to measure perform

25-by excellence mdles. Tqm magazine vo 1.6. not 2001.

26-Robert $\mathrm{H}$. : Why strategies New York, times, Planning yoes away 1990 . 35. Mathew D. Shank : Sport Marketing , A Strategic Perspective , Prentice Hall , 1999. 